\title{
La mitocrítica de Gilbert Durand: teoría fundadora y recorridos metodológicos
}

\author{
Fátima GUTIÉRREZ \\ Universidad Autónoma de Barcelona \\ fatima.gutierrez@uab.cat
}

Recibido: 01/06/2011

Aceptado: 27/07/2011

\section{Resumen}

Desde la teoría (orígenes y metodología) y la práctica (Lautréamont y el Decadentismo), estas reflexiones se proponen situar el método y la escuela de crítica literaria que crea Gilbert Durand en el ámbito epistemológico que le corresponde, muy lejos de un comparativismo que parece querer negar su carta de naturaleza, si bien, paradójicamente, sirviéndose de su nombre, el de mitocrítica.

Palabras clave: Gilbert Durand. Mitocrítica. Mitoanális. Nouvelle Critique. Lautréamont. Decadentismo.

\section{La mythocritique de Gilbert Durand : théorie fondatrice et parcours méthodologiques}

\begin{abstract}
Résumé
D'un point de vue tant théorique (origines et méthodologie) que pratique (Lautréamont et le Décadentisme), ces réflexions veulent situer la méthode d'analyse littéraire ainsi que l'école critique créées par Gilbert Durand dans l'espace épistémologique qui est le leur, bien loin d'un comparatisme qui, paradoxalement, en se servant de son nom, celui de mythocritique, semble vouloir nier son essence même.
\end{abstract}

Mots clés: Gilbert Durand. Mythocritique, Mythanalyse. Nouvelle Critique. Lautréamont. Décadentisme.

\section{Gilbert Durand's Mythocritic: Foundational Theory and Methodological Survey}

\begin{abstract}
Through an exposition of the origins and methodology of the literary criticism school developed by Gilbert Durand, along with an applied analysis of the works of Lautréamont and the Decadent movement, this article aims to bring the mythanalysis back to the place where it belongs. In so doing, it will show how the label mythocritic has been appropriated and misused to represent a mere comparativist effort, far from its original purpose and meaning.
\end{abstract}

Key words: Gilbert Durand, mythocritic, mythanalysis, Nouvelle Critique, Lautréamont, Decadent movement. 


\section{Referencia normalizada}

Gutiérrez, F., (2012) "La mitocrítica de Gilbert Durand: teoría fundadora y recorridos metodológicos". Thélème, Vol. 27, 175-189.

Sumario: Unos orígenes no tan lejanos. El nacimiento de una escuela crítica. La mitocrítica, el mitoanálisis y sus respectivas "mitodologías".

Il est des pensées subalternes et d'autres dont on sait, ou l'on "sent", qu'elles s'inscrivent dans la durée. Celle du Professeur Gilbert Durand est du nombre qui prodigua un manna absconditum à tous ceux qui, avec discernement, surent s'en inspirer

M. Maffesoli

Sin duda, el último libro publicado por Gilbert Durand: La sortie du XXe siècle (2010) invita a una reflexión sobre la teoría que él mismo empezara a crear a mediados del pasado, y aún tan cercano, siglo XX, y que inauguró su magistral ensayo: Les Structures anthropologiques de l'imaginaire (1960), sólido cimiento del imponente edificio epistemológico que supondrán sus posteriores trabajos. Pero esta reflexión se hace tanto más necesaria cuanto que, desde hace algún tiempo, venimos observando la utilización indiscriminada del término mitocrítica; utilización que muy poco, o nada, tiene que ver con el concepto que establece Gilbert Durand y cultiva su escuela. Si tuviéramos que poner una fecha al inicio de esta confusión terminológica y metodológica nos remontaríamos, sin duda, a 1992, con la publicación del libro de Pierre Brunel: Mythocritique. Théorie et parcours. Ya en su contraportada podemos leer: "La mythocritique n'a jamais constitué une école critique. Il s'agit plutôt d'une tendance diffuse dont les origines sont lointaines et qui a trouvé force à date plus récente dans l'entourage de Gilbert Durand".

Lógicamente, el sucinto apartado teórico que inaugura la obra de Brunel no desmiente, todo lo contrario, estas demasiado ligeras afirmaciones. En las pocas (no llegan a 9) páginas que dedica a Gilbert Durand (lo que ya resulta extraño puesto que titula su trabajo con un término que apela directamente a la teoría del mitólogo ${ }^{1}$ y que, como el propio Brunel reconoce, es creación suya), el comparatista, primero, se pierde en vaguedades para, después, cargar indiscriminadamente contra el breve

\footnotetext{
${ }^{1}$ Resulta imprescindible señalar que Gilbert Durand, inicia su carrera científica con una agregación en Filosofía para, finalmente, ocupar la cátedra de Sociología y Antropología Cultural en la Universidad de Grenoble. Sin embargo, nunca abandonará una pasión por la literatura que se manifiesta, por primera vez, en esa bellísima obra (y su tesis segunda) que se titula Le décor mythique de La Chartreuse de Parme (1961) y en la que ya nos podemos encontrar un análisis mitocrítico de la obra de Stendhal, podríamos decir que ante literam, puesto que acuñará el término una década más tarde.
} 
artículo en el que Durand emplea el término mitocrítica por primera vez: "Le voyage et la chambre dans l'oeuvre de Xavier de Maîstre. Contribution à la mythocritique" (1972). Pero resulta mucho más grave que no haga la más mínima alusión a la esclarecedora, y tan conocida, ya en aquel tiempo, para los especialistas en crítica literaria, Figures mythiques et visages de l'oeuvre de la mythocritique à la mythanalyse, ensayo publicado en 1979 (por lo tanto, ¡13 años anterior al de Brunel!), y en el que Gilbert Durand establece (en más de 300 intensas páginas, y muy especialmente en el último capítulo: "Méthodologie, mythocritique et mythanalyse"), con absoluta claridad y pertinencia, la teoría y la práctica del método tanto mitocrítico como mitoanalítico; que ya había esbozado en su obra anterior, Science de l'homme et tradition. Le nouvel esprit anthropologique (1975) y más concretamente en el capítulo "Science historique et mythologie traditionnelle» (59-90). Cabe apuntar que, en su Introduction à la mythodologie. Mythes et sociétés (1996), el mitólogo, en media página y una cita (Cf. Durand, 1996b: 191, 232-233) con la elegancia, erudición y sorna (’̀ taquin, taquin et demi!) de las que siempre ha hecho gala, reduce a cenizas la intempestiva crítica de Brunel contra su artículo sobre Xavier de Maîstre - que, por cierto, aparece recogido en la anteriormente citada Figures mythiques et visages de l'oeuvre (Durand 1979a: 157-174) - . Y decimos intempestiva porque nos resulta muy difícil entender que se sienta la necesidad de presentar un trabajo, que metodológicamente se inscribe en el tan tradicional comparativismo, bajo el atractivo nombre del que fue, y sigue siendo, uno de los más novedosos métodos de la Nouvelle Critique: la mitocrítica, y que esto se haga precisamente, atacando a su creador. Por supuesto, ni ningún crítico ni ninguna escuela crítica tienen monopolio ninguno sobre ningún concepto; sin embargo parece lógico que si se va a utilizar uno, inscrito ya en una corriente de pensamiento determinada, con un sentido perfectamente definido y sustentado por un impecable (e implacable) discurso teórico, se haga con el mismo rigor; indicando, además, como mínimo, qué es lo que se va a conservar de él (si no ¿para qué utilizarlo?, más valdría crear uno nuevo) y qué es lo que se va a aportar de original. El no seguir estas pautas sólo lleva a confusión y esto es lo que nos encamina hoy a reflexionar sobre un hecho que se remonta al 92, ya que resultó ser el punto de partida de un pozo de desconcierto que, a día de hoy y muy especialmente en nuestra Universidad, tiende a aplicar la etiqueta de mitocrítica a cualquier cosa y, concretamente tras la senda de Brunel, a un comparativismo, que puede ser del todo lícito, pero cuyo parecido con la mitocrítica que fundó (por más que se intente obviar su nombre y su magisterio) Gilbert Durand es pura coincidencia.

Dedicaremos, pues, los siguientes párrafos a revisar el concepto durandiano de mitocrítica situándolo en el muy preciso ámbito cultural en el que nace, que le es propio y que genera una incontestable y pluridisciplinaria escuela de pensamiento en la que destacan, ciñéndonos al ámbito de la crítica literaria y sin salir del territorio francés, nombres tan acreditados y obras tan prolíferas como las de Simone Vierne, Pierre Gallais, Claude-Gilbert Dubois, Gilberte Aigrisse, Philippe Walter, Joël Thomas, Françoise Bonardel, Gilbert Bosetti, Jean Perrin, Chantal Robin, Arlette Chemin y tantos otros (la lista sería interminable) que ya habían dado a 
conocer parte de sus trabajos en fechas muy anteriores al 92. Todo esto remitiéndonos únicamente, como acabamos de indicar, a la crítica literaria y al panorama francés y, por lo tanto, sin entrar - resultaría imposible por razones de espacio ni en los innumerables estudiosos extranjeros que pertenecen a la escuela ni en figuras de la sociología como Michel Maffesoli, Georges Bertin, Jean-Pierre Sironneau o Patrick Tacussel, de la psicología como Yves Durand o de la filosofía como Jean-Jacques Wunnenburger que dan brillante testimonio, sin excepción, del magisterio de Gilbert Durand.

Quizá también tendríamos que recordar, aquí, que en febrero de 1982 el mismo Gilbert Durand participó en la Semana de la Crítica Literaria: Au-delà du structuralisme, organizada por el Departamento de Francés de la Universidad Complutense y el Instituto Francés de Madrid, con una conferencia y un seminario titulados: "Mythocritique, mythanalyse, mythodologie"; tampoco se debería olvidar que el primer congreso que presidieron Gilbert Durand y Simone Vierne en Cerisy: Le mythe et le mythique se remonta a julio de $1985^{2}$ y que el CRI (Centre de Recherche sur l'Imaginaire) fue fundado en 1966 por Gilbert Durand, con la colaboración de Paul Deschamps y Léon Cellier y tiene, a día de hoy, más de un centenar de centros y de grupos de investigación asociados en los cinco continentes, de Sydney a Seúl, de Brazzaville a Lublin, de Montreal a Recife, de Lisboa a Túnez, sin olvidar Barcelona, y de cuyas actividades dan cuenta el Bulletin de liaison des Centres de Recherches sur l'Imaginaire, las Lettres électroniques $d u$ CRI y las páginas web de los CRI de Grenoble, Milán o Cluj. También habría que citar revistas especializadas de tanto prestigio como Cahiers internationaux $d u$ symbolisme, Cahiers de l'imaginaire (fundada en 1988), Iris, Eidôlon o Loxias. Tampoco podemos obviar aquí obras colectivas directamente dedicadas a Gilbert Durand y su escuela crítica como La galaxie de l'imaginaire. Dérive autour de l'oeuvre de Gilbert Durand (1980). En Introduction aux méthodes de l'imaginaire - en la que, curiosamente, participa Brunel - (1998) no puede dejar de evidenciarse, desde el título, la influencia durandiana. Pero lo que realmente nos interesa aquí es, ya lo hemos indicado, situar la mitocrítica en el lugar epistemológico que le corresponde y que de ninguna manera puede ser desligado de la figura de su creador.

${ }^{2}$ La editorial Albin Michel, en 1987 y en su colección "Cahiers de l'hermétisme”, publicó las actas con el mismo título del congreso. 


\section{Unos orígenes no tan lejanos}

La primera obra de Gilbert Durand (y su Tesis de Estado), Les Structures Anthropologiques de l'Imaginaire, se fundamenta en una teoría general de la imagen como núcleo generador de todo pensamiento racionalizado y del universo semiótico que de éste se desprende. Por lo tanto, se sitúa en una corriente cultural que parte de finales del siglo XIX con el psicoanálisis, es decir: con el primer movimiento que analiza de manera científica la psique y, con ella, la imagen y el imaginario, y en el que destacan, con sus conocidas divergencias, las imponentes figuras de Freud, Adler y Jung. Esto dará lugar a los estudios, hoy ya clásicos, de psicoanalistas como Charles Baudouin, René Laforgue, Marie Bonaparte o, más adelante, Lacan y, en lo que se refiere a la crítica literaria propiamente dicha, a la psicocrítica de Charles Mauron $^{3}$. Poco después, tanto la antropología como la sociología se unirán a esta corriente de recuperación del espacio del imaginario, haciendo un especial hincapié en el fenómeno mítico. A principios del siglo XX, el sociólogo Georges Sorel integra el concepto de mito en la realidad de su propia época, liberándolo del que era su contexto habitual: las sociedades arcaicas y la Grecia antigua, demostrando su importancia en las representaciones populares y obreras, y situándolo en la base de los grandes movimientos revolucionarios. Más cercanas en el tiempo, destacan las figuras de Roger Bastide, a quien Durand siempre reconoció como uno de sus

\footnotetext{
${ }^{3}$ Precisamente, el término psicocrítica de Charles Mauron servirá como modelo al de mitocrítica de Gilbert Durand. Pero no hay en ello una querelle de mythologues, un casi dramático Durand contre Mauron (Brunel, 1992: 47). Durand siempre ha demostrado una gran admiración hacia el creador de la psicocrítica, pero considera al psicoanálisis (que está en la base de la teoría de Mauron si bien ésta es puramente crítica y no terapéutica), como al marxismo o al estructuralismo, una hermenéutica reductora, ya que centra el objeto de su estudio en ámbitos tan reducidos como la psique del autor, las contingencias económico-sociales de su época o el soporte formal de la obra, que no dan la medida real del objeto literario (o de arte, en general). Ahora bien, Durand nunca negará los aportes de estas disciplinas (ni de otras muchas más) ni los rechazará, sino que se verán integrados en su fructífera noción de trayecto antropológico. Por otro lado, en Figures mythiques et visages de l'oeuvre ya había dejado muy claramente expuesto el porqué de su divergencia (no desavenencia) con el autor de Des métaphores obsédantes au mythe personnel: «La mythocritique s'interroge en dernière analyse sur le mythe primordial, tout imprégné d'héritages culturels, qui vient intégrer les obsessions, et le mythe personnel lui-même. Or ce fond primordial est bien un mythe, c'est-à-dire un récit, qui, d'une façon oxymoronique, réconcilie dans un tempo original, les antithèses et les contradictions traumatisantes ou simplement embarrassantes sur le plan existentiel » (Durand, 1979a : 169). Finalmente, añadir que a nadie se le pueden escapar las similitudes entre las metáforas obsesivas mauronianas y los mitemas durandianos, lo que el mitólogo es el primero en reconocer, pero resulta evidente que el mito, en la concepción de cualquier estudioso del fenómeno, nunca es personal porque siempre va más allá de la persona, sus comportamientos y su ideología. Y ya que Mauron busca, como meta de sus análisis el mito personal del creador, Durand nunca podría suscribir este concepto, para el que él propondría la expresión complejo personal (Durand, 1996: 193). De ahí a querellas y enfrentamientos hay una más que considerable distancia.
} 
maestros y, posteriormente, Michel Maffesoli, Patrick Tacussel o Georges Bertin, ya discípulos directos de Gilbert Durand y que se integran en una sociologie des profondeurs que defiende que toda sociedad es simbólica y que la presencia real y perenne del mito determina tanto la Historia como las sociedades y las culturas. También, la antropología reivindicó un interés específico por los relatos míticos y, asistida por la etnología (gracias a estudios como los de Marcel Griaule sobre los pueblos Dogon, los de Maurice Leenhardt sobre Nueva Caledonia o los de Jean Servier sobre la civilización Berebere), se encaminó hacia nuevas consideraciones en torno a este fenómeno en las que destacaron figuras de la talla de Claude LéviStrauss, fundador de la antropología estructural, del historiador de las religiones Mircéa Éliade, del mitólogo Joseph Campbell o del filólogo y gran especialista en mitología indoeuropea Georges Dumézil. Así el sermo mythicus recuperó su perdido interés demostrando su capital importancia y su funcionalidad no sólo en comunidades consideradas como primitivas sino también descubriendo su presencia en las manifestaciones culturales, sociales y políticas de toda época. La filosofía tampoco podía faltar a esta cita y lo hizo gracias a la obra de Ernst Cassirer. Su teoría hace recaer toda la originalidad del pensamiento humano en su formulación simbólica; lo que implica que es precisamente la facultad de simbolizar la que distingue al hombre de los animales (que únicamente poseen sistemas de recepción y acción) y la que, por lo tanto, constituye la antropomorfosis. Y puesto que el símbolo contradice, por su esencia misma, el principio de identidad, a la vez que afirma el principio de analogía, Harald Höffding introdujo, por primera vez, esta noción en las categorías formales, es decir, en los conceptos fundamentales del pensamiento humano, en los que no la habían incluido ni Aristóteles ni Kant. En la misma corriente filosófica de Cassirer se integró el pensamiento del islamista Henry Corbin (otro de los principales maestros de Gilbert Durand) que, en sus múltiples y esclarecedores estudios sobre literatura árabe, y especialmente iraní, descubre que gran parte de esta cultura se fundamenta sobre el concepto de relato visionario y que el imaginario o Imaginal o Mundus Imaginalis (mundo situado entre los sentidos y el espíritu, que sólo percibe y comprende la imaginación creadora), constituye la principal vía de acceso de los místicos musulmanes al universo del ser. Finalmente, la fenomenología de la imaginación poética, gracias a Gaston Bachelard - "incontestable pionnier de cette "nouvelle critique »" (Durand, 1994: 38) —, de quien Durand siempre se consideró un muy directo discípulo, profundiza en el valor y la significación ontológicos de la imagen y en su primacía sobre el pensamiento, situándola en el origen mismo de la consciencia.

Como acabamos de ver, los orígenes de la mitocrítica no son tan lejanos.

\section{EI nacimiento de una escuela crítica}

También la crítica artística en general y literaria en particular se unirán a este nuevo paradigma epistemológico. Ya, hacia los años 50, sufrían un enorme cambio gracias a la aparición del estructuralismo, es decir, de una corriente metodológica que se 
alzaba en contra de los métodos historicistas hasta entonces imperantes. El estructuralismo - quizá fuera más exacto decir los estructuralismos - presentó nuevas perspectivas de análisis que obligaban a una sistematización, a un centrarse en el objeto de estudio, dejando de lado circunvalaciones, a veces, inútiles. Gracias a ellos, el saber literario tomó la trinchera que la anterior crítica histórica había cavado al rededor del texto impidiendo llegar a su profundidad, a su inmanencia, ya que, en multitud de ocasiones, se detenía más en todo lo que pivotaba en torno a la obra, en todo lo que transcendía a la obra, que en la obra en sí. A su vez, los distintos estructuralismos nos demostraron que el signo es "in-significante" en sí mismo, que dice en relación con su emplazamiento en el interior de una estructura, que no existe aislado, que todo es estructura o forma parte de una estructura y como tal debe ser tratado, en la obra total, en la cosmogonía verbal de su creador, más allá de la palabra, la frase, la página o el capítulo, incluso más allá de la obra única. Sin embargo, estos métodos resultaron reductores ${ }^{4}$ al no ofrecer más que la superficie exterior del objeto literario; su estudio se limitaba a la combinación y articulación de las estructuras formales de las que está compuesto. Por lo tanto, se hizo necesario aplicar otra mirada, más profunda, sobre la obra. El estudio del aparato formal llamaba a nuevos análisis que, mediante la estructura, nos devolvieran el sentido, el significado del texto literario a través de las imágenes, de las figuras que se manifiestan en las palabras que lo componen. Desde esta voluntad de recuperación del sentido del objeto artístico, nació el estructuralismo figurativo, método que parte del estudio de la imagen, y que, con el transcurrir del tiempo, terminó llamándose mitocrítica, pero no adelantemos acontecimientos.

El estructuralismo figurativo surge de Les structures anthropologiques de l'imaginaire de Gilbert Durand. En esta obra, el autor se propuso establecer, en primer lugar, un sistema de clasificación de las imágenes y, con ellas, de todo el capital, potencial y primero, del Imaginario. Como sólo se pueden clasificar, ordenar, aquellas realidades que participen de algo, que tengan algo en común, partiendo de lo que tiene en común la especie Homo Sapiens: los reflejos dominantes postural, nutricional y sexual, Durand propone estos reflejos como referentes primeros de las imágenes. Estos constituirán unos vectores, unos grandes conjuntos, unas matrices semánticas, si se quiere, unos soportes anatómico/fisiológicos ${ }^{5}$ en donde se va a

\footnotetext{
${ }^{4}$ Sobre lo que Gilbert Durand considera "hermenéuticas reductoras" es especialmente esclarecedor su ensayo: L'imagination symbolique (1964) y, dentro de él, el capítulo III: "Les herméneutiques réductives" (Durand, 1964: 38-57). En cuanto a su crítica sobre el estructuralismo, resulta de obligado cumplimiento la lectura de su lúcido y muy ameno artículo "Les chats, les rats et les structuralistes" incluido, como capítulo III, en su obra Figures mythiques et visages de l'oeuvre (Durand, 1979a: 84-144).

${ }^{5} \mathrm{Si}$ se quiere, los soportes anatómico/fisiológicos de nuestras representaciones. Lo que ya habían intuido tanto Jung como Éliade, pero que Durand confirma científicamente (y he aquí una de las más grandes aportaciones de su teoría) y lleva a la conclusión de que todo lo que es instintivo, reflexológico, en la especie Homo Sapiens, trae aparejado un proceso de simbolización.
} 
integrar todo nuestro potencial de representación. Precisamente a estas matrices les dio el nombre de estructuras antropológicas del imaginario. Estas estructuras, también llamadas regímenes, aglutinan todas las posibles manifestaciones de las imágenes y definen la concreción del Imaginario; concreción en la que se encuentran indisolublemente unidos los contenidos y las formas, en una intención significante. De esta manera, las consideraciones lógicas que el estructuralismo formal hacía recaer sobre la rigidez hueca de la estructura se fueron llenando de una significación, de un sentido intrínseco al propio concepto de imagen: núcleo generador de todo pensamiento racionalizado. Podríamos decir que, para el estructuralismo figurativo, en el principio — del pensamiento—está la imagen ${ }^{6}$.

Acabamos de ver, por lo tanto, de qué manera y bajo qué postulados de base surge, dentro de la (ya no tan novedosa) Nouvelle Critique, la escuela de crítica literaria que crea Gilbert Durand y en la que destacan los nombres que ya citamos en los primeros párrafos de este escrito. Pero, naturalmente, toda escuela crítica se define por su metodología.

\section{La mitocrítica, el mitoanálisis y sus respectivas "mitodologías"}

El estructuralismo figurativo abarca tanto la mitocrítica como el mitoanálisis. Si nos referimos a la mitocrítica, estamos hablando de un procedimiento concreto de análisis artístico basado en los postulados teóricos del estructuralismo figurativo, pero no necesariamente tenemos que incidir en el terreno del mitoanálisis que, sin embargo, se asienta sobre los mismos principios. Por otra parte, tanto la mitocrítica como el mitoanálisis pueden ser aplicados a todas las artes, mientras que el estructuralismo figurativo es esencialmente pluridisciplinario, lo que ya ha demostrado su operatividad en campos tan aparentemente dispares como la matemática (René Thom), la sociología (Michel Maffesoli) o la psicoterapia (Yves Durand), por poner unos pocos ejemplos.

En el ámbito exclusivo de la crítica literaria podemos definir la mitocrítica como un método de lectura crítica que analiza el texto literario de la misma manera que se analiza un mito, puesto que ya nos enseñó el historiador de las religiones (y novelista) Mircéa Éliade que el mito es, en cierto modo, el modelo de cualquier relato $^{7}$. Esto, en muchos casos, favorece el descubrimiento de estructuras míticas,

\footnotetext{
${ }^{6}$ Para Gilbert Durand, el concepto de figura es sinónimo del de imagen y lo empleó refiriéndose a la famosa querella entre arte figurativo y arte no figurativo, que se hallaba en pleno auge en el momento en el que apareció su primera obra. Empleamos aquí el término imagen, en su sentido más amplio, de representación de un objeto. Toda obra literaria no es más que un enorme recital de imágenes encarnadas en la palabra.

${ }^{7}$ A lo que Gilbert Durand hace referencia en numerosas ocasiones, por ejemplo: « Dans un premier moment, il est un peu futile - quoique honnête! — de chercher des ancêtres à notre méthode. De
} 
patentes o latentes, inherentes al texto, que habrá que buscar, analizar e interpretar. Sin embargo, parece que hay que seguir insistiendo en que no se trata de ir al encuentro, por ejemplo, del mito de Orfeo o de Sísifo en determinada narración o en un conjunto de obras. Ése ha sido, y sigue siendo, el terreno de la prestigiosa crítica histórica/comparatista, se la llame como se la quiera llamar, en determinados casos, probablemente con una intención de "modernización" que, por su brillante hacer de siglos, de ninguna manera, necesita. La mitocrítica, repito puesto que es un punto de partida básico que parece no terminar de comprenderse, estudia el objeto literario como se estudia el mito (partiendo, como veremos, de los análisis propuestos por Lévi-Strauss).

Por su parte, el mitoanálisis ampliará el campo de la mitocrítica, ya que su finalidad es la de descubrir cuáles son los mitos patentes o latentes que atraviesan, "trabajan", o sustentan un determinado momento cultural. Con estas dos definiciones ya podemos adentrarnos en la mitodología, en la forma de operar del muy preciso método que crea Gilbert Durand.

Así pues, la mitocrítica se refiere a un análisis textual que sigue las mismas pautas del análisis mítico; pero, ¿por qué?, ¿qué pone en relación a la obra literaria con el mito? y ¿cuáles son esas pautas?

Las primeras preguntas tienen una respuesta muy sencilla, que ya hemos esbozado. Además de que, como ya vimos, el mito sea el modelo de cualquier relato (o, quizá, por ello) toda literatura tiene en común con el sermo mythicus el ser un relato simbólico, una creación simbólica a través del lenguaje; por lo tanto, resulta lógico aplicar un mismo método a objetos si no idénticos, al menos, muy similares. ¿Cómo procede ese método? Gilbert Durand nos indica ${ }^{8}$ que, en un primer momento, el

tout temps, on c'est aperçu qu'un récit, qu'il soit poétique, romanesque ou dramatique, avait une parenté avec le sermo mythicus. Ils possèdent la même structure; je souligne que je prends ce terme au sens le plus banal : celui d'éléments et de procédures de con-struction, et non au sens technique des linguistes et des sémioticiens contemporains » (Durand, 1996 : 185-186).

${ }^{8}$ Y no precisamente en una sola de sus obras sino en: Figures mythiques et visages de l'oeuvre (el ensayo íntegro está dedicado a la teoría y, sobre todo, a la práctica de la mitocrítica y del mitoanálisis, ya que teoría y práctica nunca se separan en la epistemología durandiana ); Science de l'homme et tradition (obra más enfocada al porqué de la crisis de las ciencias humanas y a la propuesta de un Nuevo Espiritu científico que huya de las reducciones dualistas de nuestra tradición occidental, pero en la que no falta un apartado que se presenta como "Esquisse et programme d'une mythocritique"; L'âme tigrée. Les pluriels de psyché (de un cariz, primero más literario pero, después, más filosófico; destacaríamos, sin embargo, en ella, los capítulos "Structure et figure pour un structuralisme figuratif" y "Le regard de psyché de la mythanalyse à la mythodologie"; Mito, simbolo e mitodologia y Mito e Sociedade (ambas son recopilaciones de conferencias pronunciadas por Gilbert Durand en la Universidad Nova de Lisboa, con un eminente carácter didáctico), Beaux-arts et archétypes (enfocada en brillantísimos estudios mitocríticos y mitoanalíticos de obras pictóricas y musicales); L'imaginaire. Essai sur les sciences et la philosophie de l'image (en la que se podría destacar el apartado: "Les « Nouvelles Critiques»: de la mythocritique à la mythanalyse"); Introduction à la mythodologie. Mythes et Sociétés (el título lo dice todo); Champs de l'imaginaire (en esta recopilación de artículos, 
aplicar la grille que constituyen los tres regímenes de la imagen (heroico, místico y sintético, según Les structures anthropologiques de l'imaginaire) nos servirá para ordenar, agrupar las imágenes, los símbolos ${ }^{9}$, que conforman un texto, en constelaciones simbólicas que no harán sino desvelar las redundancias ${ }^{10}$ del mismo (muy cercanas a lo que Mauron llama "metáforas obsesivas"). Estas redundancias nos indicarán los mitemas que constituyen la estructura del texto; lo que permite una lectura sincrónica del objeto de estudio, que toma como modelo inicial el método de Lévi-Strauss, tal y como éste trata el mito de Edipo en su Anthropologie structurale $^{11}$. Pero la interpretación no se puede quedar en poner de relieve, como lo pretende Lévi-Strauss, la estructura del mito. Más allá de su diacronía y de su sincronía, habrán de ser analizadas las combinatorias de situación de los personajes y los espacios por los que se mueven — sus decorados míticos, en términos de Durand-, así como su evolución, para lo que será especialmente útil un análisis simbólico del relato (que obvia Lévi-Strauss), un tercer momento metodológico, tertium datum semántico, que nos revele el sentido del texto, ya que es la interpretación del mismo la meta de toda lectura crítica.

reunidos por Danielle Chauvin, es especialmente relevante y esclarecedor, para nuestro propósito, el titulado "Pas à pas mythocritique". Finalmente, su última obra publicada, La sortie du XXe siècle, es, en su primera parte, una recopilación de las obras en las que más extensamente se recoge su metodología: Introducción à la mythodologie y Figures mythiques et visages de l'oeuvre.

${ }^{9}$ Esto no significa una vacilación en el uso de la terminología, entendemos la imagen como una representación mental (que, por lo tanto, pertenece al ámbito de lo abstracto) mientas que el símbolo es un signo que actualiza la imagen, de ahí su plurivocidad (que hereda de ella) y, con ella, esa eterna capacidad de generar sentido que lo distingue de todos los demás signos.

${ }^{10}$ La redundancia, como descubre y demuestra Lévi-Strauss, profundiza Paul Ricœur y subraya Gilbert Durand, es la esencia del mito y, por lo tanto, la clave de toda interpretación mitológica: "Le sermo mythicus n'étant ni un discours démonstratif (...) ni un récit narratif (...) doit utiliser la persuasion par l'accumulation obsédante de " paquets », « d'essaims » ou de " constellations » d'images. Dès lors, par delà le fil obligé de tout dis-cours (la diachronie), ces redondances, bien proches de l'esprit musical de la variation, peuvent être regroupées en séries synchroniques, qui nous fournissent les «mythèmes », c'est-à-dire les plus petites unités sémantiques signalées par des redondances" (Durand, 1996: 194).

${ }^{11}$ Lévi-Strauss entresaca del mito de Edipo sus motivos redundantes, sus mitemas. Después, agrupa estos mitemas, relacionados por un rasgo común, en columnas que, leídas en horizontal y de izquierda a derecha, muestran la diacronía del relato, y leídas en vertical, considerando cada columna como un todo, desvelan su sincronía. En el caso del mito de Edipo y, siempre según Lévi-Strauss, la primera columna agruparía el inhabitual desarrollo de ciertos lazos de parentesco que unen a diferentes personajes, las luchas a muerte entre los componentes de una misma familia, la muerte de diferentes monstruos telúricos y la dificultad que tienen distintos personajes para andar, lo que se pone de manifiesto únicamente en la etimología de los nombres propios. Ya que estas columnas presentan esas relaciones contradictorias, que permiten al creador de la antropología estructural definir el mito como un discurso dilemático, éste no sería más que un juego lógico del que se serviría la sociedad primitiva para resolver sus propias contradicciones (Cf. Lévi-Strauss, 1958: 236 y ss.). 
Vayamos a un, necesariamente breve, ejemplo de estructura mitémica ${ }^{12}$.

Si analizamos con la metodología mitocrítica Les chants de Maldoror de Lautréamont observaremos cómo, de esta obra, emergen una serie de mitemas, que agrupan imágenes y estructuras arquetípicas que se repiten significativamente a lo largo de la misma, son:

—La perversión del héroe (en las dos acepciones del término "pervertir": "viciar con malas doctrinas o ejemplos las costumbres, la fe, el gusto, etc." (DRAE) y "perturbar el orden o estado de las cosas" —DRAE-) verificada tanto en los continuos actos criminales del protagonista como en su "santificación" del crimen mismo.

- El aburrimiento (muy en relación con las teorías de Schopenhauer) de un ocioso Maldoror que se manifiesta, además y especialmente, a través de esa angustiosa búsqueda del semejante, del otro, que ocupa un lugar privilegiado en la obra.

- La fascinación por el fracaso y la ruina que se proyecta en las reiterativas imágenes de las ruinas invadidas por una naturaleza desordenada y parásita, así como en la enfermedad de los cuerpos y las almas.

- La mujer fatal que aparece en el Primer Canto como la Prostitución (con la que pacta Maldoror), se despide de la obra en la figura de una Circe convertida en la bola que empuja un monstruoso escarabajo y se llega a encarnar hasta en la figura de la madre, generalmente considerada arquetipo de máximas virtudes y, aquí, pura abyección.

- La renuncia al amor, como resolución lógica del mitema precedente, también se hace reiterativamente explícita a lo largo de toda la obra y, a la vez, desarrolla un discurso erótico/materialista (exento de todo sentimiento amoroso) dominado por la perversión sexual.

- La muerte como decadencia será el sexto mitema que se despliegue en los cantos de un Maldoror que se complace en la enfermedad, en la sangre, la agonía y el martirio, demostrando, a lo largo de toda la obra, una especial predilección

\footnotetext{
${ }^{12}$ Cabe también precisar que el concepto de mitema es mucho más amplio en Gilbert Durand que en Lévi-Strauss. Para el mitólogo, estas unidades mínimas y redundantes de significación pueden ser, como se indica en Figures mythiques et visages de l'oeuvre, al analizar el mito de Hermes: un objeto emblemático (en el caso de este dios, las alas que lleva no sólo en el casco, sino también en los talones y en el caduceo, lo que refuerza su naturaleza de intermediario entre los dioses y los hombres, entre el cielo y la tierra) o una estructura arquetípica cuyo contenido puede ser un acto, una situación o un decorado; por ejemplo, el tema del robo, ya que Hermes roba los rebaños de Apolo o los tendones de Zeus que guarda el gigante Tifón, o de los trueques: Hermes cambia la lira por los rebaños de Apolo o la siringa por el cayado de oro del mismo dios.
} 
por las cabezas cortadas que lleva al protagonista hasta asistir, entre los vapores del sueño, a su propia muerte por decapitación.

Todos los mitemas que vemos emerger de Les chants de Maldoror coinciden absolutamente con los que Gilbert Durand tipifica como propios del Mito de Hero$d e s^{13}$, que suele fascinar a las estéticas finiseculares y que domina el panorama artístico europeo, al acabar el siglo XIX, síntoma de esa crisis profunda en el alma de Occidente, que desveló Spengler. Todo ello tiene su enclave simbólico en las mórbidas y nocturnas estructuras místicas del imaginario decadente - por supuesto, utilizamos estos términos en su pleno sentido durandiano - , de las que Les Chants de Maldoror resultan ser un perfecto ejemplo.

Pero ya hemos avanzado que del estructuralismo figurativo también surgirá el mitoanálisis. Éste amplía el campo de la mitocrítica al proponerse desvelar cuáles son los mitos dominantes o los mitos en tensión en una determinada época de la cultura, lo que desemboca en un análisis socio histórico.

La metodología mitoanalítica parte de la mitocrítica, pero en vez de analizar un solo texto, estudia un conjunto representativo de obras pertenecientes a la misma época cultural. Para ello, se va ampliando el esquema, conformado por los diferentes mitemas pertenecientes a una obra literaria, escrita en un lugar y en un momento determinados, añadiéndole los mitemas de otros textos surgidos en el mismo lugar y en el mismo momento. Así, de este nuevo esquema, emergerán rasgos comunes no estereotipos exclusivamente regulados por la moda -, conjuntos de obsesiones culturales, mitos de época, diría Gilbert Durand, que caracterizan los momentos de tensión creativa en la que se desarrollan las distintas etapas de la historia de la cultura. Pero, el mitoanálisis no debe reducirse al estudio único de la literatura, sino que habría de ser ampliado por el análisis de las distintas obras de creación surgidas de las diferentes artes que se desarrollan en el mismo lugar y en el mismo momento histórico.

En relación con la metodología mitoanalítica, algunos de los más brillantes y esclarecedores trabajos de Gilbert Durand ${ }^{14}$ han desarrollado su concepto de cuenca semántica, uno de los postulados más operativos del mitoanálisis, en el que ha sistematizado lo que ya habían intuido pensadores como Quinet, Nietzsche, D'Ors, Sorokin o Spengler, y que no está muy lejos del concepto de campos morfogenéticos que postuló la obra del biólogo Rupert Sheldrake.

\footnotetext{
${ }^{13}$ Como podemos ver, principalmente, en el capítulo 9 de Beaux-arts et archétypes: "Hérode et le mythe décadent" (Durand, 1989: 163-180).

${ }^{14}$ Entre los que destacaríamos: "La beauté comme présence paraclétique. Essai sur les résurgences d'un bassin sémantique", in Eranos 1984. Frankfurt, Insel Velag, 1986, pp. 127-173; "La sortie du XXème siècle", in AA.VV., La liberté de l'esprit. Pensées hors du rond. №.12. París, Hachette, 1986, pp. 70-97; L'imaginaire. Essai sur les sciences et la philosophie de l'image. París, Hatier, 1994, pp. 61-66; Introduction à la mythodologie. Mythes et sociétés. París, Albin Michel, 1996, pp. 79-130.
} 
Una cuenca semántica es una estructura — con todo el sentido de dinamicidad que el estructuralismo figurativo le da a este término- sociocultural, identificada por regímenes específicos de la imagen y mitos dominantes —que le dan nombre y la tipifican - que corresponde a un contorno común, delimitado por una época, un estilo, una estética, una sensibilidad, en definitiva, una visión - $-\mathrm{y}$, por lo tanto, una expresión - del mundo, compartidos. La formación de estas cuencas obedece a un proceso en el que Durand destaca seis momentos, cronológicamente irregulares, caracterizados por lo que denomina metáforas potamológicas y que son: las arroyadas, la división de aguas, las confluencias, el nombre del río, la disposición de las riberas y el agotamiento de los deltas. Ya que ejemplificamos un esbozo de análisis mitocrítico por medio de la obra de Lautréamont, no nos distanciaremos del Decadentismo, por lo que, a continuación, propondremos un esbozo de análisis mitoanalítico de la cuenca semántica que le es propia.

Las arroyadas serían las distintas corrientes que se forman en un momento cultural preciso y que, a veces, son resurgimientos lejanos de una misma cuenca semántica, $\mathrm{y}$, otras veces, nacen de determinadas circunstancias históricas como guerras, invasiones o grandes acontecimientos sociales, científicos y/o culturales. En lo que se refiere al Decadentismo, en 1818 aparece la decisiva obra de Schopenhauer, El mundo como voluntad y como representación, no muy bien acogida por una estética y un pensamiento románticos dominados por la figura de Hegel, que se sitúa prácticamente en las antípodas de las del pensador de Dantzig. Sin embargo, la semilla de Schopenhauer germinará, de un modo asombroso, justo a su muerte, en 1860. Con ella nos encontramos ante una primera arroyada, de orden cultural, de la cuenca semántica del Decadentismo, que se intensificará gracias a un buen número de acontecimientos históricos que, en la segunda mitad del siglo XIX y en los albores del XX, nos presentan una Europa que cambia, a marchas forzadas, su vieja fisonomía: la tradicional Rusia entona aires revolucionarios; cae el poder austrohúngaro; entre coros verdianos se forja la nación italiana; en Francia se suceden revoluciones, monarquías y la Segunda República, hasta desembocar en los fastos de opereta de un Segundo Imperio que llama al desencanto y da paso a una vacilante Tercera República.

Cuando las distintas arroyadas se escinden en partidos, escuelas o corrientes y se generan entre ellos diversos enfrentamientos con otros de diferente orientación, podemos hablar ya de división de aguas. Es la fase de las querellas, de las rivalidades y, también, de los mutuos enriquecimientos. Las aguas artísticas del XIX, en Europa, vienen muy crecidas, pocos momentos históricos muestran una mayor diversidad de movimientos culturales. Un ejemplo característico es el de Francia: en la segunda mitad de un siglo que asistió, primero al Romanticismo de la interiorización, de clara influencia alemana, después al de la energía y al advenimiento del Realismo, entre estruendosas querellas, surge, en cierto modo fruto de la fracasada Revolución del 48, un tercer Romanticismo que sienta las bases del Simbolismo en las obras del Hugo del exilio, Nerval y Baudelaire, que también han bebido de la perfección formal de la Escuela Parnasiana. Mientras tanto, en Europa, una nueva estética se enfrenta, temática y verbalmente, a la de los románticos en obras y 
artistas tan variados y, en principio, tan dispares como la Salambô de Flaubert, Les chants de Moldoror de Lautréamont, el Inno a Satana de Carducci y, más adelante, los Buddenbrooks y Der Tod in Venedig de Thomas Mann; los lienzos de Gustave Moreau, las óperas de Richard Strauss o de Camille Saint-Saens. Esta nueva estética obedecerá a un perfil común que tomará cuerpo en un nuevo mito de cultura: el Decadente, así entramos en el tercer momento de una cuenca semántica, es el momento de las confluencias.

De la misma manera que un río está formado por afluentes que enriquecen y afianzan su caudal, una corriente de cultura precisa del apoyo y del reconocimiento de personalidades, en algunos casos autoridades, influyentes. Todo mito de civilización requiere una apoyatura social y/o histórica y, en este caso, la encontramos en la paradigmática figura del rey loco de Baviera, Luis II, benefactor y amigo de artistas, amante, no por casualidad, del novelista austriaco Sacher- Masoch.

El cuarto momento de una cuenca semántica surge cuando un mito, una leyenda, un personaje real o ficticio, le da nombre. En el caso del Decadentismo, Gilbert Durand propone, para tipificar este espacio cultural, el mito de Herodes Antipas. Frente al generoso Prometeo romántico, se yergue el viejo y pervertido rey, manchado de sangre, acusado de incesto por el Bautista, dubitativo y confuso, que calma su tedio deleitándose en la sensual danza de una maléfica Salomé, hija de la no menos perversa Herodías, la esposa que desea ver, sobre una bandeja, la cabeza cortada de aquél que, siguiendo la ley mosaica, se atrevió a acusarla de incesto.

La disposición de las riberas dará cuenta de una consolidación estilística, filosófica, racional. Es el momento de los teóricos y, en este caso, el primero que formula los parámetros decadentes es, en 1882, Paul Bourget en su obra Essais de psychologie contemporaine. Dos años más tarde, J. K. Huysmans ofrece, en À rebours, un auténtico manual novelado del Decadentismo, mientras Anatole Baju, en 1887, lanza, secundado en un primer momento por Paul Verlaine, la etiqueta historiográfica de École Décadente. En 1918, a la par que finaliza la Gran Guerra, desde el ámbito de la filosofía biologista, Spengler nos presenta la summa teórica de $L a$ decadencia de Occidente. Gilbert Durand hace coincidir estos dos acontecimientos con el fin del periodo sociocultural en el que se desarrolla la cuenca semántica que tipifica el mito decadente y que, como ya se ha indicado, comenzaba alrededor de 1860. Entramos, así, en lo que el mitólogo llama "el agotamiento del los deltas".

Es el momento del declive, en el que se forman meandros, derivaciones, en el que la corriente del río debilitado se divide, se deja captar por corrientes vecinas -que, en nuestro caso sería, en su mayor parte, la del Simbolismo-y/o desemboca en el mar del olvido. Es emblemática, del agotamiento de los deltas del Decadentismo la última e inacabada ópera de Puccini, Turandot.

A los que conocen la obra de Gilbert Durand no les puede pasar desapercibida la enorme rentabilidad que ofrece la metodología mitoanalítica en todo lo que se refiere a los estudios comparativos, tanto de las distintas literaturas como de las diferentes artes. Lástima que los que utilizan hoy, a nuestro juicio inadecuadamente, el concepto de "mitocrítica", a la vez que se autoproclaman "mitocríticos", no lo han descubierto aún. 
Creemos haber llegado a la meta de nuestra reflexión que era la de demostrar que la mitocrítica es una escuela crítica (en un primer momento, y durante bastante tiempo, precisamente fue conocida como École de Grenoble) que crea Gilbert Durand y que, lejos de ser una "tendencia difusa", se sirve, como todo método crítico, de una muy precisa metodología que, por supuesto, ha ido evolucionando y enriqueciéndose a lo largo del tiempo gracias a los múltiples y brillantes trabajos de su incontestable fundador desde Les structures anthropologiques de l'imaginaire (1960) hasta La sortie du XXe siècle (2010):

D'une science de l'homme réunifiée autour d'une double application - mythocritique et mythanalytique - méthodologique (que nous étions tentés d'écrire dès lors "mythodologique ») émergeaient les prolégomènes d'une orientation épistémologique et philosophique nouvelle, non pas d'une nouveauté fugace de mode du "prêt à porter» intellectuel, mais nouvelle en tant que renouvelée par les retrouvailles des mythes, des sensibilités, des philosophèmes occultés (Durand, 1996a: 146).

\section{REFERENCIAS BIBLIOGRÁFICAS}

Brunel, P., (1992) Mythocritique. Théorie et parcours. Paris, PUF, Coll. Écriture.

Durand, G., (1960) Les structures anthropologiques de l'imaginaire. Paris, Bordas.

Durand, G., (1961) Le décor mythique de La Chartreuse de Parme. Paris, José Corti.

Durand, G., (1964) L'imagination symbolique. Paris, PUF.

Durand, G., (1979a) Figures mythiques et visages de l'oeuvre. De la mythocritique à la mythanalyse. Paris, Berg.

Durand, G., (1979b) Science de l'homme et tradition. Le nouvel esprit anthropologique. Paris, Berg.

Durand, G., (1981) L'âme tigrée. Les pluriels de psyché. Paris, Denoël.

Durand, G., (1982) Mito, simbolo e mitodologia. Lisboa, Presença.

Durand, G., (1983) Mito e Sociedade. A mitanalise e a sociologia das profondezas. Lisboa, Regra do Jogo.

Durand, G., (1989) Beaux arts et archétypes. La religion de l'art. Paris, PUF.

Durand, G., (1994) L'imaginaire, essai sur les sciences et la philosophie de l'image. Paris, Hatier.

Durand, G., (1996a) Champs de l'imaginaire. Grenoble, ELLUG.

Durand, G., (1996b) Introduction à la mythodologie. Mythes et sociétés. Paris, Albin Michel.

Durand, G., (2010) La sortie du XXe siècle. Paris, CNRS Éditions.

Gutiérrez, F., (1987) "Los abismos del verbo: Lautréamont y el mito decadente" in Barcarola. №49, pp. 215-233.

Lautréamont, (1969) Euvres complètes. Les chants de Maldoror. Poésies. Paris, Garnier-Flammarion.

Lévi-Strauss, Cl., (1958) Anthropologie structurale. Paris, Plon. 